\title{
Solid-phase synthesis of graphitic carbon nanostructures from iron and cobalt gluconates and their utilization as electrocatalyst supports $\dagger$
}

\author{
M. Sevilla, ${ }^{a}$ C. Salinas Martínez-de Lecea, ${ }^{b}$ T. Valdés-Solís, ${ }^{a}$ E. Morallón ${ }^{c}$ and A. B. Fuertes* ${ }^{a}$ \\ Received 27th September 2007, Accepted 12th December 2007 \\ First published as an Advance Article on the web 10th January 2008 \\ DOI: $10.1039 / b 714924 \mathrm{~g}$
}

\begin{abstract}
We present a novel and facile synthesis methodology for obtaining graphitic carbon structures from $\mathrm{Fe}(\mathrm{II})$ and $\mathrm{Co}$ (II) gluconates. The formation of graphitic carbon can be carried out in only one step by means of heat treatment of these organic salts at a temperature of $900{ }^{\circ} \mathrm{C}$ or $1000{ }^{\circ} \mathrm{C}$ under inert atmosphere. This process consists of the following steps: (a) pyrolysis of the organic gluconate and its transformation to amorphous carbon, (b) conversion of $\mathrm{Fe}^{2+}$ and $\mathrm{Co}^{2+}$ ions to $\mathrm{Fe}_{2} \mathrm{O}_{3}$ and $\mathrm{CoO}$ and their subsequent reduction to metallic nanoparticles by the carbon and (c) conversion of a fraction of formed amorphous carbon to graphitic structures by $\mathrm{Fe}$ and $\mathrm{Co}$ nanoparticles that act as catalysts in the graphitization process. The removal of the amorphous carbon and metallic nanoparticles by means of oxidative treatment $\left(\mathrm{KMnO}_{4}\right.$ in an acid solution) allows graphitic carbon nanostructures (GCNs) to be selectively recovered. The GCNs thus obtained (i.e. nanocapsules and nanopipes) have a high crystallinity as evidenced by TEM/SAED, XRD and Raman analysis. In addition, we used these GCNs as supports for platinum nanoparticles, which were well dispersed (mean Pt size 2.5-3.2 nm). Most electrocatalysts prepared in this way have a high electrocatalytical surface area, up to $90 \mathrm{~m}^{2} \mathrm{~g}^{-1} \mathrm{Pt}$, and exhibit high catalytic activities toward methanol electrooxidation.
\end{abstract}

\section{Introduction}

Interest in porous carbon materials has recently increased due to their potential use in many emergent applications, such as gas storage, gas separation, as catalytic supports, as specific adsorbents and as electrodes in electrochemical double layer capacitors or Li-ion batteries. ${ }^{1}$ Optimal utilization of carbon materials in these areas depends to a large extent on their physical properties, which must be conveniently adjusted to the specific requirements of each application. For this reason, in recent years a number of synthesis strategies have been developed to prepare carbons with controlled physical characteristics. One such strategy is the nanocasting technique, which has been extensively employed to synthesize mesoporous carbons with well-defined structural properties, such as pore size, particle size, morphology or porosity. ${ }^{2}$ For certain applications it is the crystallinity of the carbon framework that

\footnotetext{
${ }^{a}$ Instituto Nacional del Carbón (CSIC), P. O. Box 73, 33080-Oviedo, Spain.E-mail: abefu@incar.csic.es; Fax:+34 9852976 62; Tel: + 34985118970

${ }^{b}$ Departamento de Química Inorgánica, Universidad de Alicante, Apartado 99, 03080 Alicante, Spain

${ }^{c}$ Departamento de Química Física e Instituto Universitario de Materiales, Universidad de Alicante, Apartado 99, 03080-Alicante, Spain

$\dagger$ Electronic supplementary information (ESI) available: Thermogravimetric weight profiles for the decomposition of $\mathrm{Fe}(\mathrm{II})$ gluconate and Co(II) gluconate under nitrogen (Fig. S1). XRD patterns of Co(II) gluconate and $\mathrm{Fe}(\mathrm{II})$ gluconate carbonized at different temperatures (Fig. S2). TEM microphotographs of $\mathrm{Co}$ (II) gluconate pyrolyzed at $730{ }^{\circ} \mathrm{C}$ and $\mathrm{Fe}(\mathrm{II})$ gluconate pyrolyzed at $900{ }^{\circ} \mathrm{C}$, before and after metal removal (Fig. S3). $\mathrm{N}_{2}$ adsorption isotherm for a GCN together with the $\alpha_{s}$ plot obtained for this isotherm (Fig. S4). TGA curves of the Pt/GCNs and Pt/Vulcan (Fig. S5). See DOI: 10.1039/b714924g
}

plays a critical role. Specifically, the use of carbon materials as electrocatalytic supports requires materials with the following characteristics: (a) a high electronic conductivity, (b) an accessible porosity and (c) a good resistance to oxidation at low temperatures. ${ }^{3}$ These properties can be found in carbon materials with nanostructures (i.e. nanotubes, nanofibers, nanocapsules, nanocoils, etc.) that combine a high crystallinity (high graphitic order) with a very open structure that excludes framework-confined micro- and mesopores. Carbon materials with these characteristics are currently produced by means of arc discharge, ${ }^{4}$ laser vaporization ${ }^{5}$ and plasma and thermal chemical vapor deposition. ${ }^{6}$ These methods require very high temperatures $\left(>5000{ }^{\circ} \mathrm{C}\right)$, which makes them costly and complex in terms of scalability. For this reason, there is growing interest in the development of low-cost and facile synthesis processes. A simple synthesis strategy for preparing GCNs is the carbonization of carbon precursors in the presence of certain transition metals ( $\mathrm{Fe}, \mathrm{Co} \mathrm{Ni}, \mathrm{Mn}$, etc.) that act as graphitization catalysts. ${ }^{7}$ The main advantage of catalytic graphitization is that both graphitizing and non-graphitizing carbon precursors can be transformed into crystalline materials at moderate temperatures $\left(\leq 1000{ }^{\circ} \mathrm{C}\right)$, whereas conventional graphitization requires the use of graphitizing precursors and very high temperatures $>2000{ }^{\circ} \mathrm{C}$. The metal particles used as catalysts allow the non-organized carbon to be converted into graphitic carbon according to a dissolution-precipitation mechanism. ${ }^{8}$ Generally, catalytic graphitization is performed through the carbonization of polymeric materials, such as vinyl polymers, ${ }^{9}$ polyfurfuryl alcohol, ${ }^{10}$ resorcinol-formaldehyde gels $^{11}$ and phenolic resins, ${ }^{12}$ previously impregnated with a metallic salt. Recently, we 
demonstrated that other more available and cost-effective carbon precursors, such as lignocellulosic materials, can also be used for this purpose. Indeed, we obtained carbon nano structures with a high crystallinity through the carbonization of pine sawdust impregnated with $\mathrm{Fe}$ or $\mathrm{Ni}$ salts. ${ }^{13}$

The synthesis methods employed for catalytic graphitization normally require two steps: (a) impregnation of the carbon precursor with a metallic salt and (b) carbonization of the impregnated sample. The possibility of performing the catalytic graphitization in only one step is of great interest in terms of cost effectiveness and scalability. Several groups have reported a one-step synthesis scheme based on the preparation of graphitic carbon nanostructures (i.e. nanotubes or nanocapsules) by means of the pyrolysis of organometallic complexes. ${ }^{14}$ However, these precursors are expensive and in most cases they are not commercially available so they must be synthesized in the laboratory. Moreover, the procedure for synthesizing these compounds is rather complex. In short, the preparation of graphitic nanocarbons in only one step by using commercially available and cost-effective organometallic compounds still presents a challenge. Accordingly, in the present work we report a facile and one-step synthesis strategy to synthesize graphitic carbon nanostructures (GCNs). This methodology is based on the use of commercially available iron or cobalt organic salts (i.e. Fe(II) gluconate and $\mathrm{Co}$ (II) gluconate) as carbon precursor. Obviously these compounds provide both the metal catalyst for the graphitization and the carbon source. This methodology has two important advantages over the two-step synthesis methods described above: (a) the synthesis of graphitic carbon requires only one step that consists of the carbonization of the organic salt (the impregnation step is circumvented) and (b) the metal is dispersed throughout the carbon precursor matrix at a molecular level, which will theoretically lead to an enhancement of the catalytic efficiency. In addition, we investigated the application of such prepared GCNs as supports for Pt nanoparticles and their electrocatalytic performance in fuel cell processes, such as methanol oxidation.

\section{Experimental}

\section{Synthesis of graphitic carbons}

$\mathrm{Fe}(\mathrm{II})$ gluconate dihydrate (11.6 wt \% iron) and $\mathrm{Co}(\mathrm{II})$ gluconate trihydrate $(11.7 \mathrm{wt} \%$ cobalt $)$ were purchased from Aldrich and Wako, respectively. These substances were pyrolyzed under $\mathrm{N}_{2}$ at $900{ }^{\circ} \mathrm{C}$ or $1000{ }^{\circ} \mathrm{C}\left(3{ }^{\circ} \mathrm{C} \mathrm{min}^{-1}\right)$ for $3 \mathrm{~h}$. The metallic particles present in the pyrolyzed products were dissolved by $\mathrm{HCl}(10 \%)$ for $15 \mathrm{~h}$. The carbon samples thus obtained consisted of a mixture of amorphous carbon and graphitic carbon nanostructures (GCNs). In order to extract pure GCNs, the catalytically graphitized carbons were oxidized (under reflux for $2 \mathrm{~h}$ ) in an acid solution of potassium permanganate with a composition (molar) of $\mathrm{H}_{2} \mathrm{O}: \mathrm{H}_{2} \mathrm{SO}_{4}$ : $\mathrm{KMnO}_{4}=1: 0.02: 0.006$. The solid products were separated by centrifugation and washed with abundant distilled water. Finally, the precipitate was treated with $10 \% \mathrm{HCl}$ to remove the $\mathrm{MnO}_{2}$. The recovered graphitic carbon samples were denoted as GGFe-X and GGCo-X, X being equal to 900 or
1000 corresponding to the temperature used during heat treatment $\left(900{ }^{\circ} \mathrm{C}\right.$ or $\left.1000{ }^{\circ} \mathrm{C}\right)$.

\section{Preparation of Pt/GCNs electrocatalysts and electrochemical measurements}

Platinum catalysts were synthesized as reported elsewhere. ${ }^{13,15}$ In brief, poly(vinylpyrrolidone), PVP, (Aldrich) mixed with water was added to a dispersion of the carbon support in ethylene glycol (ethylene glycol : water solution, $3: 1(\mathrm{v} / \mathrm{v})$; PVP : $\mathrm{Pt}=0.15(\mathrm{w} / \mathrm{w}))$. Then, a predetermined amount of the Pt precursor $\mathrm{H}_{2} \mathrm{PtCl}_{6} \cdot 6 \mathrm{H}_{2} \mathrm{O}$ (ca. $40 \% \mathrm{Pt}$, Aldrich) was mixed with the dispersion and ultrasonicated for $10 \mathrm{~min}$. The amount of $\mathrm{Pt}$ precursor was adjusted to ensure the desired Pt mass was loaded into the catalyst (v.g. $20 \mathrm{wt} \%$ ). The $\mathrm{Pt}$ precursor concentration in the solution was kept constant at $0.002 \mathrm{M}$. The platinum ions were reduced by refluxing the polyol solution (at $\sim 140{ }^{\circ} \mathrm{C}$ ) for $1 \mathrm{~h}$ under continuous magnetic stirring. The prepared catalyst was labeled by adding $\mathrm{Pt}$ to the nomenclature used for the carbon samples. Carbon black powder (Vulcan XC-72R, Cabot International) with a BET surface area of $270 \mathrm{~m}^{2} \mathrm{~g}^{-1}$ was used as a reference support so that the performance of the prepared catalysts could be compared.

The electroactive $\mathrm{Pt}$ surface area (ESA), was measured by cyclic voltammetry (CV) using an EG\&G Parc Mod. 175 Universal Programmer and a Potentiostat Mod. $101 \mathrm{HQ}$ Instruments. A common three-electrode electrochemical cell was employed in these experiments. A $0.5 \mathrm{M} \mathrm{H}_{2} \mathrm{SO}_{4}$ solution was used as the electrolyte. A $0.3 \mathrm{~cm}$ diameter glassy carbon stick from Carbone Lorraine served as the working electrode (GC) and a platinum wire was used as the counter electrode. All the potentials were quoted against the reversible hydrogen electrode (RHE) immersed in the same solution as that used as the electrolyte. The GC was polished and washed ultrasonically with ultrapure water. The catalyst ink, consisting of the catalyst and a Nafion solution $(5 \%(\mathrm{w} / \mathrm{w})$, Aldrich) in acetone $(10 \mathrm{mg}$ catalyst per $\mathrm{L}$ and $33 \%$ Nafion), was dropped onto the GC and left to dry. Nitrogen was bubbled through the solution for the purpose of deaeration for $20 \mathrm{~min}$ prior to the measurements and this atmosphere was maintained during the experiments. The CVs were recorded at a scan rate of $50 \mathrm{mV} \mathrm{s}^{-1}$ at room temperature. Prior to this, scans at $200 \mathrm{mV} \mathrm{s}^{-1}$ up to $1.2 \mathrm{~V}$ were performed in order to clean the Pt of the catalyst layer.

To estimate the ESA parameter from the CV plots, the following equation was employed: ESA $\left[\mathrm{cm}^{2} \mathrm{~g}^{-1} \mathrm{Pt}\right]=$ $Q /\left(m_{\mathrm{Pt}} \cdot q_{\mathrm{H}}^{0}\right)$, where $Q$ is the electrical charge $(\mathrm{mC})$ obtained by integrating of the voltammetric curve between $0.05 \mathrm{~V}$ and $0.45 \mathrm{~V}$ after the correction of the double layer charge, $m_{\mathrm{Pt}}[\mathrm{g} \mathrm{Pt}]$ is the actual loading of Pt into the catalyst, and $q_{\mathrm{H}}^{0}$ is the charge for a monolayer of one electron adsorption-desorption process on Pt equal to $0.210 \mathrm{mC} \mathrm{cm}^{-2}$. ${ }^{15,16}$

To evaluate the activity of the supported catalysts in relation to the methanol electrooxidation, $\mathrm{CV}$ experiments at $50 \mathrm{mV} \mathrm{s}^{-1}$ and chronoamperometric experiments were performed on a EG\&G Potentiostat Galvanostat Mod. 263A. A solution of $0.1 \mathrm{M} \mathrm{CH} \mathrm{CH}_{3} \mathrm{OH}(99.8 \%$, Merck) in $0.5 \mathrm{M} \mathrm{H}_{2} \mathrm{SO}_{4}$ was used. 


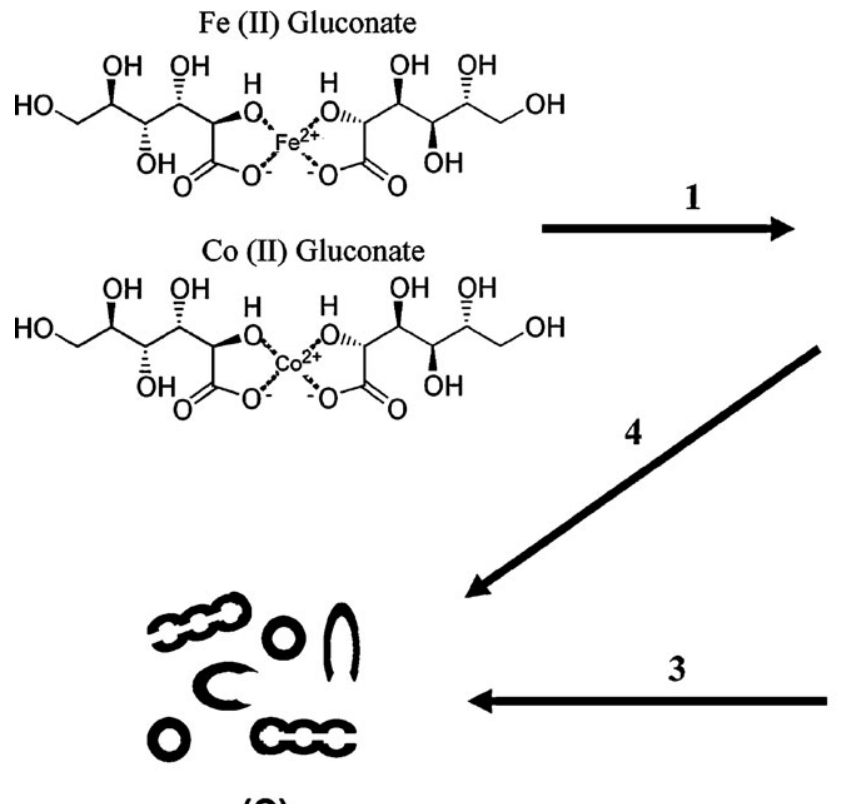

(C)

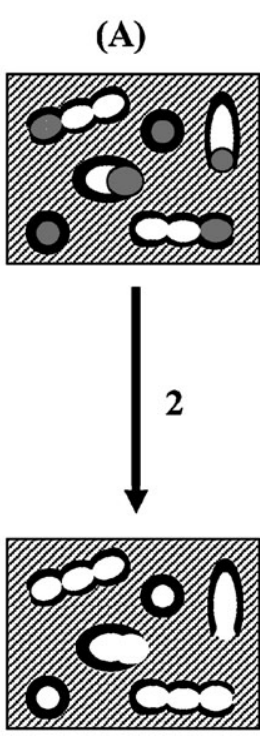

(B)

\section{GCNs $\square$ Amorphous carbon $\bigcirc \mathrm{Fe} / \mathrm{Co}$ particles}

Fig. 1 Illustration of the synthesis procedure for the GCNs obtained from iron and cobalt gluconates. (a) Carbonized samples containing Fe or Co nanoparticles; (b) Sample A without metallic nanoparticles; (c) Graphitic carbon nanostructures. (1) Thermal decomposition of gluconates, formation of metallic nanoparticles and catalytic graphitization of a fraction of amorphous carbon; (2) Removal of metallic nanoparticles (HCl); (3) Removal of amorphous carbon by oxidation with $\mathrm{KMnO}_{4}$ in an acid medium; (4) Removal of the metallic nanoparticles (2) and the amorphous carbon (3) can be carried out in only one step (4) by means of oxidation with $\mathrm{KMnO}_{4}$ in an acid medium.

\section{Characterization}

X-ray diffraction (XRD) patterns of the GCNs were obtained on a Siemens D5000 instrument operating at $40 \mathrm{kV}$ and 20 $\mathrm{mA}$, using $\mathrm{CuK} \alpha$ radiation $(\lambda=0.15406 \mathrm{~nm})$. XRD patterns of the Pt catalysts were obtained on a Seifert JSO-DEBYEFLEX 2002 instrument, using $\mathrm{CuK} \alpha$ radiation. Transmission electron micrographs (TEM) and selected area electron diffraction (SAED) patterns of the GCNs were taken on a JEOL (JEM-2000 FX) microscope operating at $200 \mathrm{kV}$. The dispersion and size of the Pt particles were evaluated by means of the TEM images (JEOL (JEM-2010) microscope operating at $200 \mathrm{kV}$ ). Two to five hundred particles were measured for each sample in order to obtain statistically significant results. High resolution transmission electron micrographs (HRTEM) were taken on a JEOL (JEM-3000 F) microscope operating at $300 \mathrm{kV}$. The Raman spectra were recorded with a Horiva (LabRam HR-800) spectrometer. The source of radiation was a laser operating at a wavelength of $514 \mathrm{~nm}$ and a power of $25 \mathrm{~mW}$. The loadings of Pt into the catalysts were determined by thermogravimetric analysis (TGA), which was performed in a Setaram 92-16.18 under air (heating rate: $10{ }^{\circ} \mathrm{C} \mathrm{min}^{-1}$ ). $\mathrm{X}$-ray photoelectron spectroscopy (XPS) of the catalysts was carried out by means of a VG-Microtech Multilab spectrometer, using $\mathrm{MgK} \alpha(1253.6 \mathrm{eV})$ radiation from a double anode with an energy flow of $50 \mathrm{eV}$. Adsorption measurements of the graphitized carbons were performed using a Micromeritics ASAP 2010 volumetric adsorption system. The external surface area $\left(S_{\text {ext }}\right)$ was estimated by means of the $\alpha_{\mathrm{s}}$-plot method and a nongraphitized carbon black was used as a reference. ${ }^{17}$

\section{Results and discussion}

\section{Structural properties of graphitic carbon nanostructures}

The overall synthesis method for preparing graphitic carbon nanostructures (GCNs) with iron and cobalt gluconates as precursors is schematically illustrated in Fig. 1. By means of thermogravimetric analysis (see Fig. S1, ESI) $\dagger$ we found that around $60 \%$ of the carbon of gluconate salts is retained in the pyrolyzed solid product, the rest being eliminated as gaseous species (i.e. $\mathrm{CO}, \mathrm{CO}_{2}$, etc.). Parallel to the decomposition of organic gluconate, the highly dispersed (at a molecular level) $\mathrm{Fe}^{2+}$ and $\mathrm{Co}^{2+}$ ions are converted to $\mathrm{Fe}_{2} \mathrm{O}_{3}$ and $\mathrm{CoO}$ at $T<$ $300{ }^{\circ} \mathrm{C}$ as evidenced by the XRD patterns (see Fig. S2, ESI). $\dagger$ These metallic oxides are made up of small nanoparticles dispersed throughout the carbonaceous material, so they exhibit weak XRD peaks (see Fig. S2, ESI). $\dagger$ At a temperature of around $600{ }^{\circ} \mathrm{C}$, the iron and cobalt oxides are partially reduced to metallic nanoparticles of $\mathrm{Co}$ and $\alpha-\mathrm{Fe}$ as deduced from the XRD patterns shown in Fig. S2 (ESI). $\dagger$ For the samples obtained at $T>700{ }^{\circ} \mathrm{C}$, the presence of metallic nanoparticles is clearly revealed by the XRD peaks displayed in Fig. S2 (ESI). $\dagger$ The TEM image obtained for the sample produced at $730{ }^{\circ} \mathrm{C}$ indicates that the $\mathrm{Co}$ nanoparticles are well dispersed throughout the carbonaceous matrix (Fig. S3a, ESI) $\dagger$ As the temperature rises, the iron and cobalt nanoparticles grow. At temperatures of $\sim 900-1000{ }^{\circ} \mathrm{C}$ they have a size in the 30-120 $\mathrm{nm}$ range, as revealed by the TEM images shown in Fig. S3d (ESI) $\dagger$ and deduced from the XRD patterns obtained for the metal-carbon composites (Fig. S2, ESI) $\dagger$ 


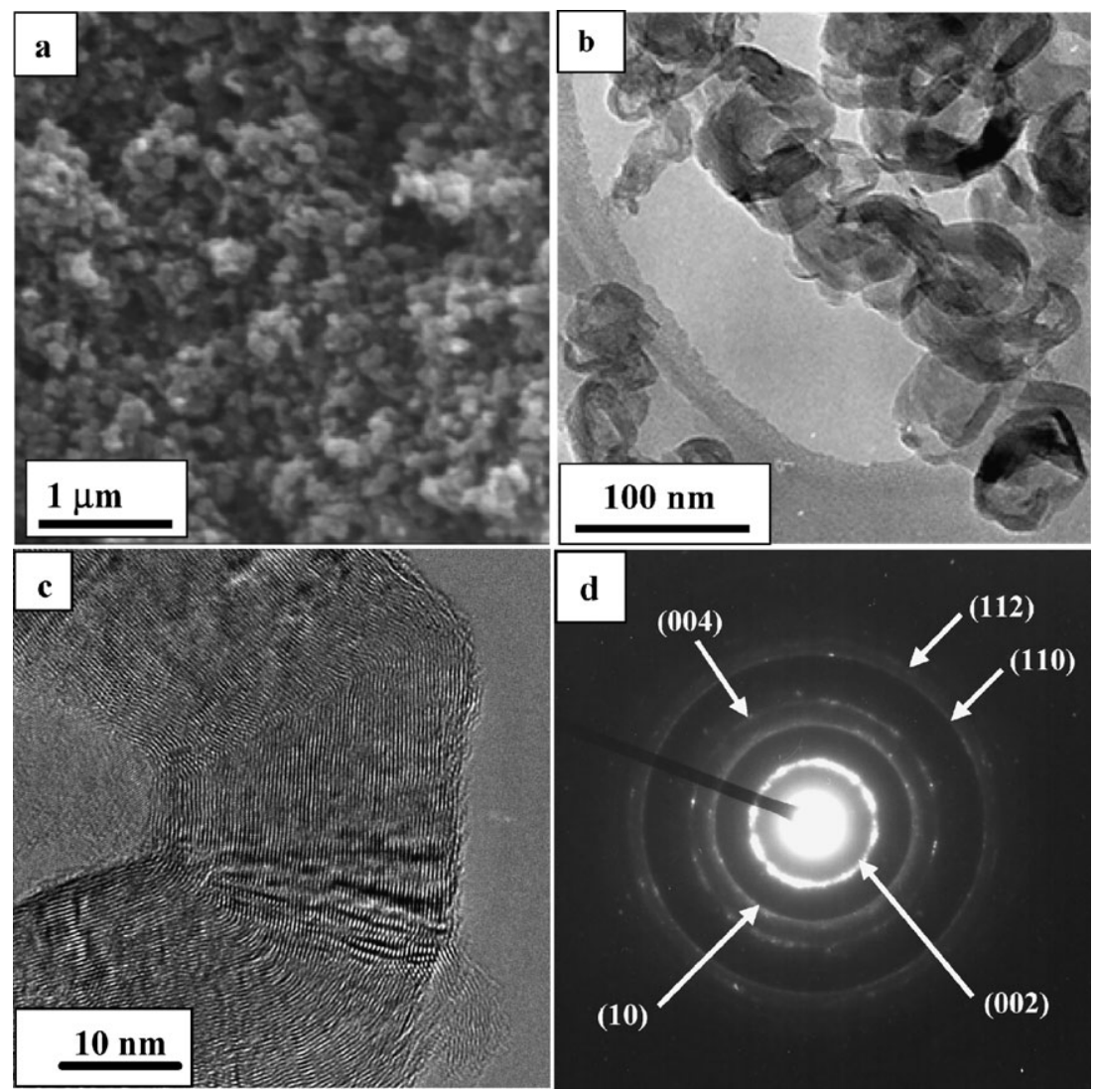

Fig. 2 (a) SEM, (b) TEM, (c) HTREM and (d) SAED of graphitic carbon nanostructures obtained from Co(II) gluconate pyrolyzed at $1000{ }^{\circ} \mathrm{C}$.

Furthermore, the structural characteristics of the carbon present in the pyrolyzed products change with the temperature, as is shown by the X-ray diffraction analysis and TEM inspection of the samples. Thus, for carbonization temperatures $<700{ }^{\circ} \mathrm{C}$, the carbon obtained has a non-organized structure (amorphous). At temperatures $>700{ }^{\circ} \mathrm{C}$ graphitic carbon is formed as revealed by the appearance in the XRD pattern of a sharp (002) reflection characteristic of graphitic carbon (see Fig. S2, ESI). $\dagger$ This result is corroborated by the TEM images obtained for the sample prepared by the pyrolysis of Co(II) gluconate at $730^{\circ} \mathrm{C}$ (see Fig. S3b and S3c, ESI). $\dagger$ The graphitic carbon in these samples is produced from the amorphous carbon which is in contact with the metallic nanoparticles, the latter acting as graphitization catalysts according to a dissolution-precipitation mechanism. ${ }^{7 a, 8,10}$ On the other hand, the carbon located far from the metallic nanoparticles retains its amorphous structure. As a consequence, the material obtained after the pyrolysis of the gluconate salts is made up of metallic nanoparticles dispersed throughout a carbonaceous matrix, consisting of a mixture of graphitic and amorphous carbon. In accordance with the graphitization scheme described above, the graphitic carbon nanostructures formed are close to the Fe and Co nanoparticles. This is supported by the TEM images of the products obtained after the decomposition of the gluconates (see Fig. S3b and S3d, ESI). $\dagger$ The metallic nanoparticles can be completely removed by treating the pyrolyzed samples with an acid $(\mathrm{HCl})$. In this case, the acid washed product consists of a mixture of graphitic and amorphous carbon (see Fig. S3c and S3e, ESI) $\dagger$ In order to obtain pure graphitic carbon structures, the carbonized samples were treated with $\mathrm{KMnO}_{4}$ (dissolved in an acid medium), which selectively converts the amorphous carbon into soluble products. The graphitic carbon is then extracted as a solid residue. We found that the carbonized samples contain a weight ratio (amorphous carbon) : (graphitic carbon) of $\sim 1$. Moreover, we observed that, independently of the type of gluconate, the yield of GCNs is $\sim 8 \mathrm{wt} \%$ (based on the weight of the gluconate salt). The SEM images shown in Fig. 2a and 3a reveal that the graphitic carbon thus obtained is composed of nanoparticles. More specifically, whereas the Co(II) gluconate leads to globular graphitic nanostructures $<100 \mathrm{~nm}$ (Fig. 2a), the Fe(II) gluconate gives rise to cylindrical structures (length up to 1 $\mu \mathrm{m}$, diameter: $\sim 100-150 \mathrm{~nm}$ ) (Fig. 3a). Close examination of these nanostructures by TEM indicates that the material obtained from $\mathrm{Co}$ (II) gluconate consists of capsules (diameter: $\sim 40-50 \mathrm{~nm}$, shell thickness: $\sim 10-30 \mathrm{~nm}$ ) (see Fig. 2b) and that derived from $\mathrm{Fe}(\mathrm{II})$ gluconate has a tubular-like morphology (diameter: $\sim 150 \mathrm{~nm}$, wall thickness: $\sim 10-25 \mathrm{~nm}$ ) (see Fig. 3b). These nanostructures have a high crystallinity, as demonstrated by the high-resolution transmission electronic microscopy images (Fig. 2c and 3c), which display very welldefined (002) lattice fringes, and also by the selected area electron diffraction patterns shown in Fig. 2d and 3d.

X-ray diffraction patterns of the GCNs synthesized at $900{ }^{\circ} \mathrm{C}$ and $1000{ }^{\circ} \mathrm{C}$ confirm that these materials are wellgraphitized (Fig. 4a). They exhibit well-resolved XRD peaks at $2 \theta \sim 26^{\circ}, 43^{\circ}, 54^{\circ}$ and $78^{\circ}$, which are assigned to the (002), (10), (004) and (110) diffractions of the graphitic framework, 


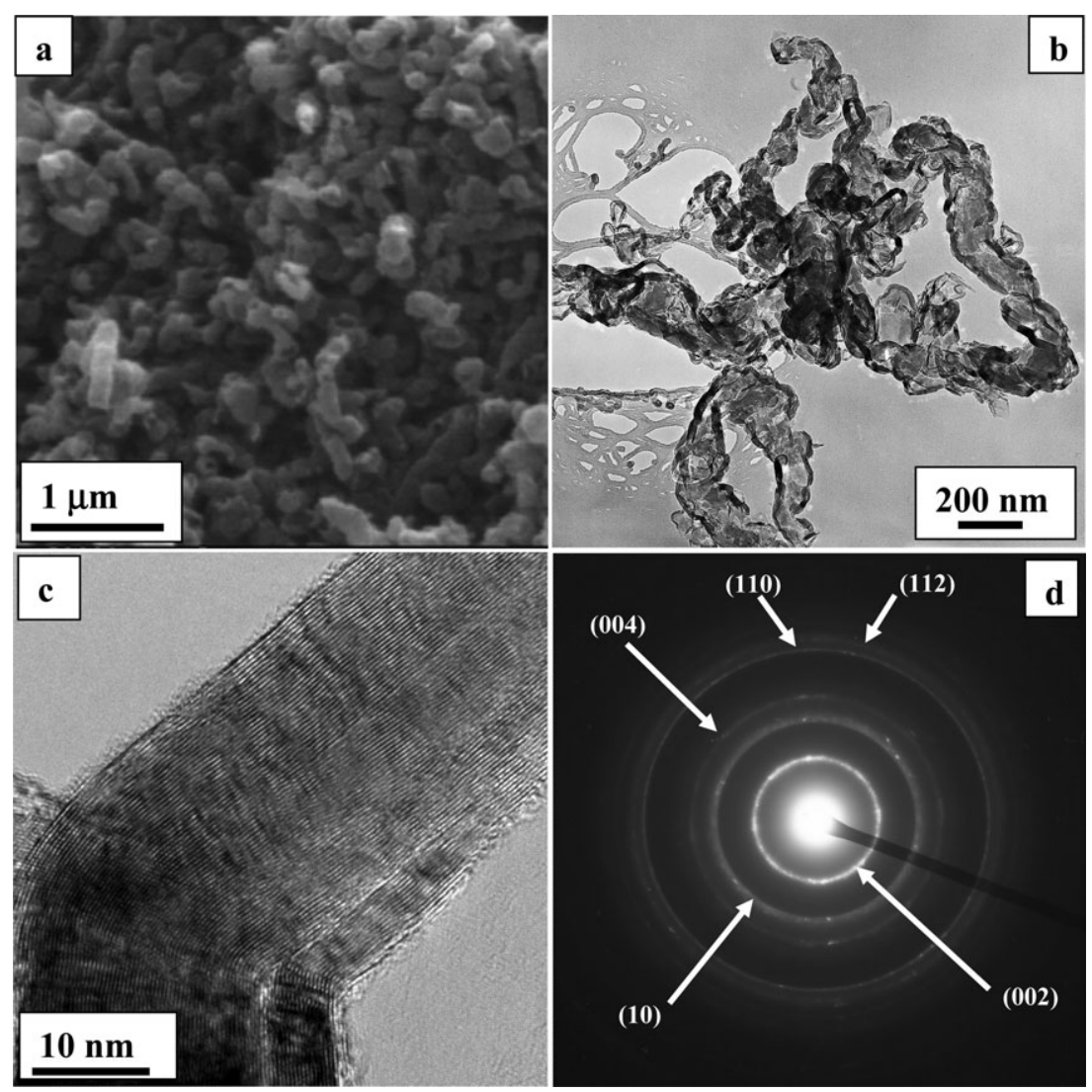

Fig. 3 (a) SEM, (b) TEM, (c) HTREM and (d) SAED of graphitic carbon nanostructures obtained from Fe(II) gluconate pyrolyzed at $1000{ }^{\circ} \mathrm{C}$.

respectively. The structural parameters of these GCNs (i.e. $d$-spacing (002) and the crystallite sizes along the $c$-axis, $L_{c}$, and $a$-axis, $L_{a}$ ) are listed in Table 1 . The values obtained for the $d$-spacing of $\sim 0.339-0.342 \mathrm{~nm}$ are larger than the graphite value $(0.3354 \mathrm{~nm})$, suggesting that the stacking of the graphene layers has experienced some distortion (turbostratic structure). ${ }^{18}$ The sizes of the graphitic crystallites $L_{c}$ and $L_{a}$ are around $10 \mathrm{~nm}$ and $20-30 \mathrm{~nm}$, respectively. The first-order Raman spectra obtained for the GCNs corroborate the high crystallinity of these materials (Fig. 4b). Indeed, they exhibit a high-intensity sharp band at $\sim 1575 \mathrm{~cm}^{-1}$ ( $\mathrm{G}$ band) which is associated to the $E_{2 \mathrm{~g} 2}$ vibrational mode of $\mathrm{sp}^{2}$ bonded carbon atoms (graphene sheets) and an additional weak band at $\sim 1350 \mathrm{~cm}^{-1}$ (D band) which is related to the imperfections in the graphitic $\mathrm{sp}^{2}$ carbon structures. ${ }^{19}$ Another first-order band $\mathrm{D}^{\prime}$ is observed as a shoulder on the $\mathrm{G}$ band at $\sim 1610 \mathrm{~cm}^{-1}$. Like the $\mathrm{G}$ band, the $\mathrm{D}^{\prime}$ band corresponds to a graphitic lattice mode with $E_{2 \mathrm{~g}}$ symmetry. ${ }^{19 b}$ The relative intensity ratio between the $\mathrm{D}$ and $\mathrm{G}$ bands $\left(I_{\mathrm{D}} / I_{\mathrm{G}}\right)$ and the full width at half-maximum of the $\mathrm{G}$ band $\left(\Delta \nu_{\mathrm{G}}\right)$ reflect the degree of graphitization. Low values for the $\left(I_{\mathrm{D}} / I_{\mathrm{G}}\right)$ and $\Delta \nu_{\mathrm{G}}$ parameters indicate a high degree of graphitization. ${ }^{20}$ The results obtained for the relative intensity of the two peaks $\left(I_{\mathrm{D}} / I_{\mathrm{G}}\right)$ and for the $\Delta \nu_{\mathrm{G}}$ parameter clearly indicate that the GCNs have a high degree of graphitization (see Table 1). Similar values have been previously reported for graphitized materials. ${ }^{21}$

The $\mathrm{N}_{2}$ sorption isotherms for the GCNs samples exhibit large nitrogen adsorption uptakes for relative pressures $>0.9$, which is typical of nanosized materials that do not contain
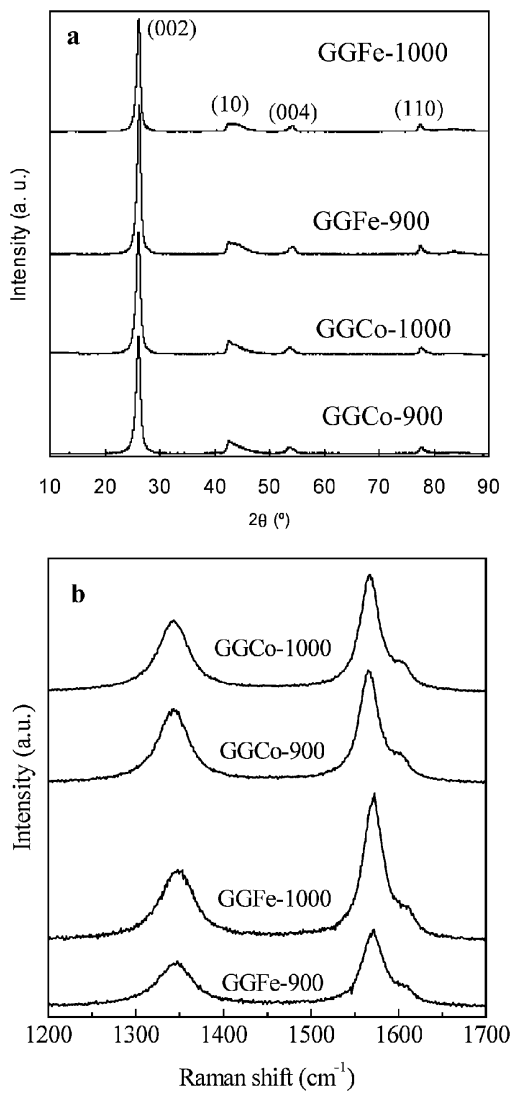

Fig. 4 (a) XRD patterns and (b) Raman spectra of graphitic carbon nanostructures. 
Table 1 Physical properties of the graphitic carbons synthesized from $\mathrm{Fe}(\mathrm{II})$ and $\mathrm{Co}(\mathrm{II})$ gluconates

\begin{tabular}{lllllll}
\hline Sample & $S_{\text {ext }} / \mathrm{m}^{2} \mathrm{~g}^{-1}$ & $d_{002} / \mathrm{nm}$ & $L_{c} / \mathrm{nm}$ & $L_{a} / \mathrm{nm}$ & $I_{\mathrm{D}} / I_{\mathrm{G}}$ & $\Delta v_{\mathrm{G}} / \mathrm{cm}^{-1}$ \\
\hline GGFe-900 & 115 & 0.339 & 9.8 & 27 & 0.816 & 28.1 \\
GGFe-1000 & 142 & 0.339 & 9.9 & 31 & 0.721 & 27.7 \\
GGCo-900 & 150 & 0.342 & 8.6 & 21 & 0.941 & 28.1 \\
GGCo-1000 & 140 & 0.341 & 8.7 & 20 & 0.914 & 26.9 \\
\hline
\end{tabular}

framework-confined pores (see Fig. S4a, ESI) $\uparrow$ This result is coherent with the morphology observed for the GCNs by means of TEM (Fig. 2b and 3b). For these samples, the adsorption only occurs at the outer surface of the nanoparticles so that not surprisingly the specific surface areas match the external surface area. Table 1 contains the values of the external surface area, which are all in the $115-150 \mathrm{~m}^{2} \mathrm{~g}^{-1}$ range as deduced by the $\alpha_{\mathrm{s}}$-plot analysis of the $\mathrm{N}_{2}$ adsorption branch (see Fig. S4b, ESI). $\dagger$ Taking into account that these materials do not contain any framework-confined pores, it can be inferred that their external surface area will be easily accessible to reactants, a characteristic which favors their application as electrocatalytic supports.

\section{Structural properties and electrocatalytic activity of Pt/GCNs}

The dispersion of Pt nanoparticles deposited on the GCNs was investigated by means of TEM. Some typical TEM images of the Pt/GCNs samples are shown in Fig. 5. These indicate that the metal nanoparticles are well-dispersed. Furthermore, the size histograms of the deposited Pt nanoparticles (Fig. 5, inset) show relatively narrow size distributions, the mean $\mathrm{Pt}$ size ranging between 2.5-3.2 $\mathrm{nm}$ (see Table 2). The Pt/GCNs samples were also characterized by powder XRD, as shown in Fig. 6a. The sharp XRD peak at $2 \theta \sim 26^{\circ}$ is associated with the (002) planes of the graphitic structure of GCNs (see Fig. 4a), while the diffraction peaks at $2 \theta=39.7^{\circ}, 46.3^{\circ}$, $67.4^{\circ}$ and $81.2^{\circ}$ can be attributed to the (111), (200), (220) and (311) planes of the face-centered cubic (fcc) structure of the $\mathrm{Pt}^{22}$ By applying Scherrer's equation to the (111) diffraction peak, it was possible to deduce the mean Pt crystallite size. The values obtained were all in the $2.2-2.9 \mathrm{~nm}$ range, and agree well with those obtained by TEM analysis (see Fig. 5, insets and Table 2).

The platinum loading of the $\mathrm{Pt} / \mathrm{GCNs}$ catalysts as deduced by TGA are in the $19.3-21.6 \mathrm{wt} \%$ range (see Table 2 ), close to the theoretical amount used in the preparation of the samples $(20 \%)$. The weight loss curves obtained for the oxidation of $\mathrm{Pt} /$ Vulcan and $\mathrm{Pt} / \mathrm{GCNs}$ catalysts are compared in Fig. S5 $(\mathrm{ESI}) . \dagger$ In all the cases, there is a change in the oxidation rate of the catalysts at the end of the curve. This fact can be due to the superposition of two opposed processes: (i) weight loss as a consequence of the oxidation of the support and (ii) weight increase due to the oxidation of Pt to PtO. These weight loss profiles reveal that the $\mathrm{Pt} / \mathrm{GCNs}$ samples have a better stability against oxidation than Pt/Vulcan. This is very important because carbon corrosion under an oxidative environment will undermine the durability of the catalytic system considerably. ${ }^{23}$
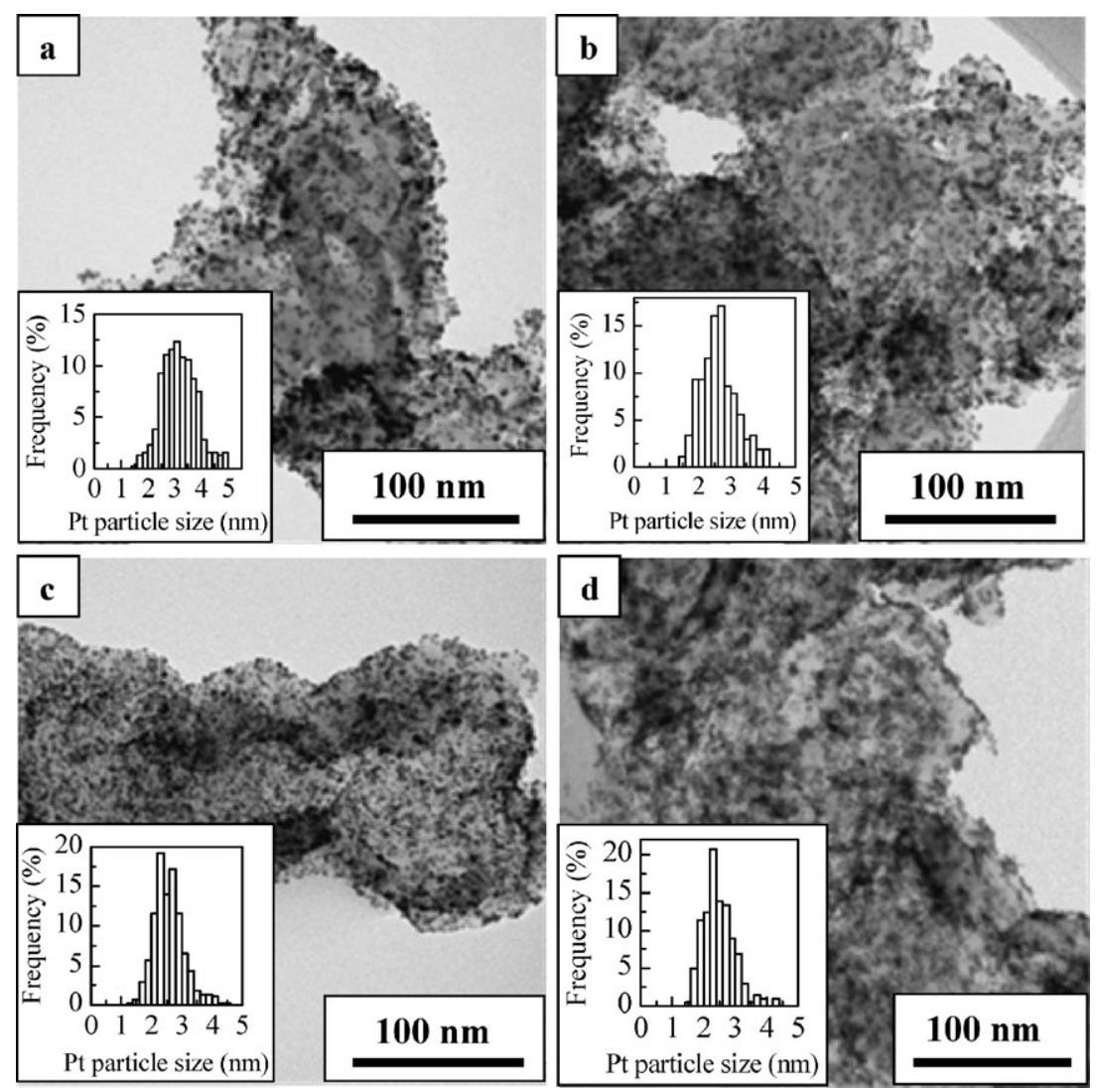

Fig. 5 TEM images of Pt/GCNs. (a) Pt/GGCo-900, (b) Pt/GGCo-1000, (c) Pt/GGFe-900 and (d) Pt/GGFe-1000. Insets: size histograms of deposited Pt nanoparticles. 
Table 2 Physical properties and catalytic activities towards the methanol oxidation of $\mathrm{Pt} / \mathrm{GCNs}$ electroctalysts

\begin{tabular}{|c|c|c|c|c|c|c|}
\hline \multirow[b]{2}{*}{ Sample } & \multirow[b]{2}{*}{$\mathrm{Pt}(\mathrm{wt} \%)$} & \multicolumn{2}{|c|}{ Pt size/nm } & \multirow[b]{2}{*}{$\mathrm{ESA} / \mathrm{m}^{2} \mathrm{~g}^{-1} \mathrm{Pt}$} & \multicolumn{2}{|l|}{ Electrocatalytic activity } \\
\hline & & $\mathrm{TEM}^{a}$ & XRD & & $I_{\mathrm{f}}($ voltam. $\exp ) / \mathrm{A} \mathrm{g}^{-1} \mathrm{Pt}$ & $I$ (chronoamp. exp) $/ \mathrm{A} \mathrm{g}^{-1} \mathrm{Pt}^{b}$ \\
\hline GGFe-900 & 20.5 & $2.6(0.5)$ & 2.2 & 90 & 185 & 68 \\
\hline GGFe-1000 & 20.6 & $2.5(0.5)$ & 2.6 & 73 & - & - \\
\hline GGCo-900 & 21.6 & $3.2(0.6)$ & 2.9 & 65 & 159 & 87 \\
\hline GGCo-1000 & 19.3 & $2.7(0.6)$ & 2.4 & 80 & 278 & 245 \\
\hline $\mathrm{Pt} /$ Vulcan & 20.9 & $2.6(0.5)$ & 2.2 & 74 & 192 & 93 \\
\hline
\end{tabular}

X-ray photoelectron spectroscopy (XPS) was used to investigate the oxidation state of the deposited platinum nanoparticles. The $\mathrm{Pt} 4 \mathrm{f}$ core level spectra of the $\mathrm{Pt} / \mathrm{GCNs}$ are shown in Fig. 6b and 6c. It can be seen that the Pt $4 \mathrm{f}$ signal consists of two doublets resulting from the spin-orbit splitting of the $4 \mathrm{f}_{7 / 2}$ and $4 \mathrm{f}_{5 / 2}$ states. The most intense pair of peaks (71.0-71.2 and 74.3-74.5 eV) is associated to metallic Pt, while the second doublet (72.4-72.7 and 75.7-76.0 eV) can be assigned to the chemical state of $\mathrm{Pt}(\mathrm{II})$. The $\mathrm{Pt}$ (II) results from the chemisorption of oxygen on the surface platinum that is in contact with air during the preparation of the catalyst. ${ }^{24}$ The binding energies of the $\mathrm{Pt}(0)$ and $\mathrm{Pt}(\mathrm{II})$ components along with the percentages are displayed in Table 3 . The percentage of each component is obtained from the relative areas of the peaks. These results reveal that metallic $\mathrm{Pt}$ is the predominant species in all the catalysts $(>70 \%)$, the proportion of $\operatorname{Pt}(0)$ in the GCNs being a bit larger than for Pt/Vulcan. This is also
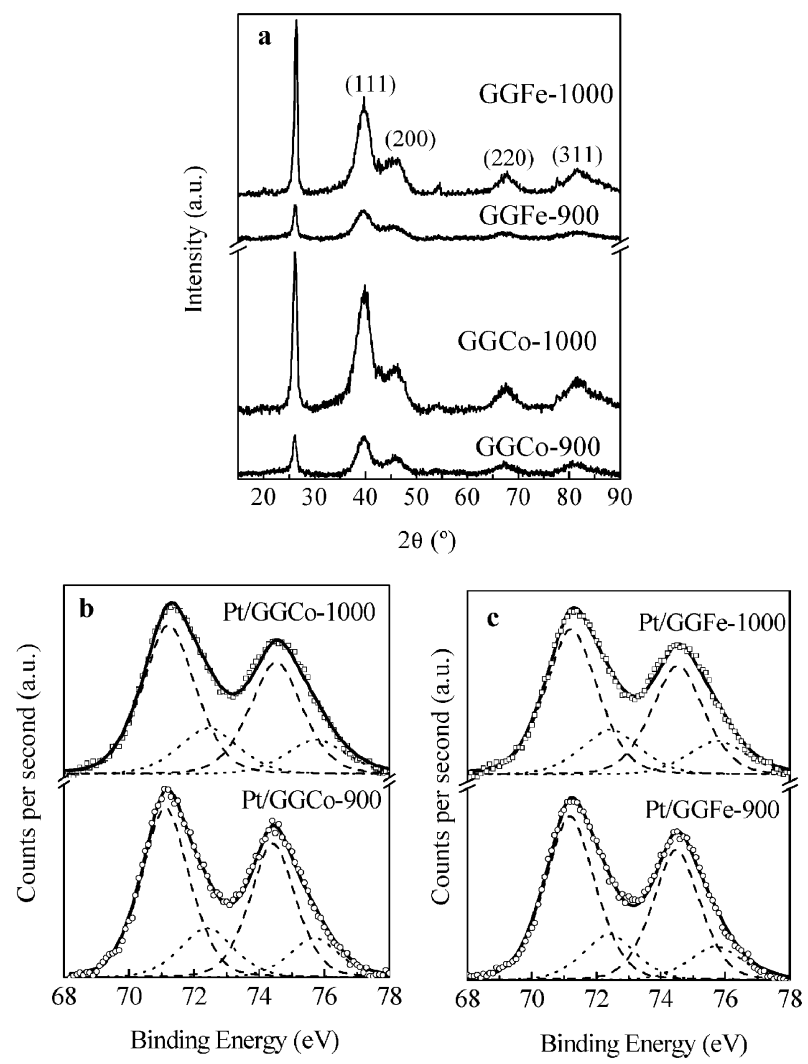

Fig. 6 (a) XRD patterns of the Pt/GCNs. (b) and (c) Pt 4f photoelectron spectra of the $\mathrm{Pt} / \mathrm{GCNs}$. important because metallic $\mathrm{Pt}$ is the catalytically active species for hydrogen or methanol electrooxidation. ${ }^{25}$

The stabilized cyclic voltammograms of the Pt/GGFe-900 and $\mathrm{Pt} / \mathrm{GGFe}-1000$ catalysts in a solution of $0.5 \mathrm{M} \mathrm{H}_{2} \mathrm{SO}_{4}$ (scan rate: $50 \mathrm{mV} \mathrm{s}^{-1}$, potential range: $0-1.2 \mathrm{~V}$ ) are shown in Fig. 7a. The voltammetric profiles are typical of a polycrystalline Pt with two well defined hydrogen and anion adsorption-desorption peaks on the different faces of the Pt in the potential range of $0.06-0.4 \mathrm{~V}$ vs. RHE. The voltammetric profiles are dissimilar, indicating the presence of a different surface structure for the platinum nanoparticles. The peak at $\sim 0.13 \mathrm{~V} v s$. RHE corresponds to the adsorption-desorption processes on the (110) Pt faces, while the peak at $\sim 0.23 \mathrm{~V} v s$. RHE corresponds to the processes on the (100) Pt faces. ${ }^{26,27}$ In the case of the prepared catalysts that consist of Pt deposited on the supports carbonized at $1000{ }^{\circ} \mathrm{C}$ (e.g. Pt/GGCo-1000 and $\mathrm{Pt} / \mathrm{GGFe}-1000)$, the voltammetric profile shows more clearly defined peaks. It can be seen that a third anodic peak has arisen between the hydrogen adsorption peaks corresponding to the (110) and (100) Pt faces. The values obtained for the electroactive surface areas of Pt (ESA) were deduced from the CV plots (see Fig. 7a), as described in the experimental section. These ESA values are summarized in Table 2. Except for the Pt/GGCo-900 sample, all of the Pt/GCNs catalysts possess similar or higher ESA than that measured for the sample used as the reference (Pt/Vulcan). The high ESA values achieved with the GCNs confirm the high dispersion of $\mathrm{Pt}$ nanoparticles, which is illustrated by the TEM images displayed in Fig. 5. The ESA values measured for the $\mathrm{Pt} / \mathrm{GCNs}$ samples are higher than those normally reported for the electrocatalysts found in the literature. ${ }^{28} \mathrm{We}$ recently obtained a similar result for a catalyst made up of Pt nanoparticles deposited on nanostructured carbon (GCNs and carbon nanofibers). ${ }^{13,29}$

The electrocatalytic activity of the Pt/GCNs towards methanol oxidation was investigated by cyclic voltammetry and chronoamperometric experiments in a $0.1 \mathrm{M} \mathrm{CH}_{3} \mathrm{OH}+$

Table 3 Binding energies of the $\operatorname{Pt}(0)$ and $\operatorname{Pt}(\mathrm{II})$ components along with the $\operatorname{Pt}(0)$ and $\operatorname{Pt}(\mathrm{II})$ contents obtained by XPS characterization

\begin{tabular}{llll}
\hline & \multicolumn{2}{l}{$\mathrm{Pt}_{4 \mathrm{f}}$} & \\
\cline { 2 - 3 } Sample & $\mathrm{Pt}(0)$ & $\mathrm{Pt}(\mathrm{II})$ & $\mathrm{Pt}(0) / \mathrm{Pt}(0+\mathrm{II})(\%)$ \\
\hline $\mathrm{Pt} /$ GGCo-900 & $71.1-74.4$ & $72.4-75.7$ & 75.6 \\
$\mathrm{Pt} /$ GGCo-1000 & $71.2-74.5$ & $72.4-75.7$ & 74.3 \\
$\mathrm{Pt} /$ GGFe-900 & $71.2-74.5$ & $72.4-75.7$ & 77.4 \\
$\mathrm{Pt} /$ GGFe-1000 & $71.0-74.3$ & $72.4-75.7$ & 72.2 \\
$\mathrm{Pt} /$ Vulcan & $71.2-74.5$ & $72.5-75.8$ & 70.0 \\
\hline
\end{tabular}



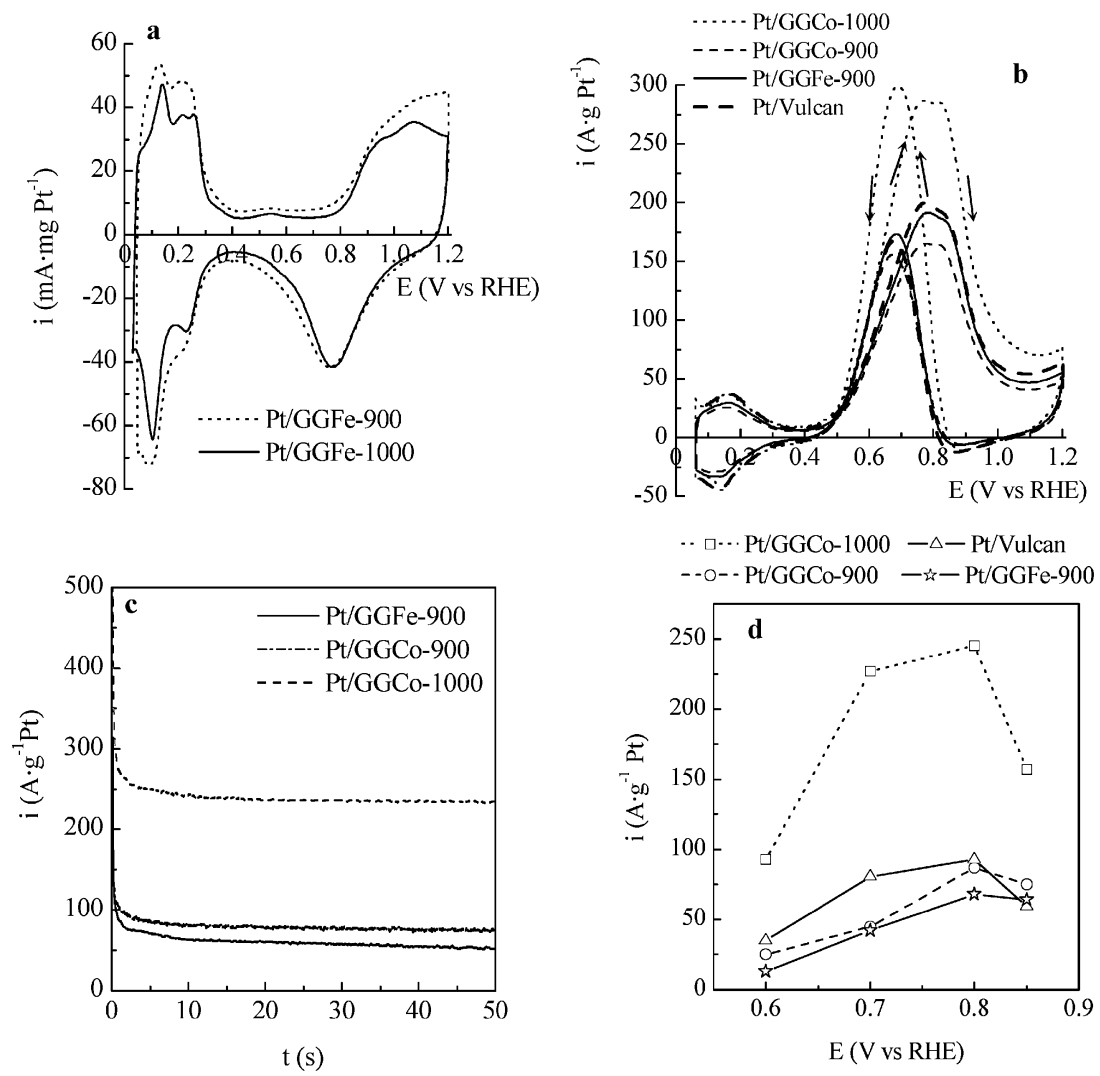

Fig. 7 (a) Cyclic voltammograms for the Pt/GGFe-900, Pt/GGFe-1000 catalysts in a $0.5 \mathrm{M} \mathrm{H}_{2} \mathrm{SO}_{4}$ solution at $50 \mathrm{mV} \mathrm{s}^{-1}$. (b) Cyclic voltammograms of room-temperature methanol oxidation on the $\mathrm{Pt} / \mathrm{GGCo}-900$ and $\mathrm{Pt} / \mathrm{GGCo}-1000$ catalysts in $0.1 \mathrm{M} \mathrm{CH}_{3} \mathrm{OH}$ in $0.5 \mathrm{M}$ $\mathrm{H}_{2} \mathrm{SO}_{4}$ at $50 \mathrm{mV} \mathrm{s}^{-1}$, (c) chronoamperometry experiments for the prepared electrocatalysts at $0.8 \mathrm{~V}$ and (d) $I$ (5 s) $-V$ curves derived from chronoamperometry experiments for the electrocatalysts prepared in a $0.1 \mathrm{M} \mathrm{CH}_{3} \mathrm{OH}+0.5 \mathrm{M} \mathrm{H}_{2} \mathrm{SO}_{4}$ solution.

$0.5 \mathrm{M} \mathrm{H} \mathrm{H}_{2} \mathrm{SO}_{4}$ solution. The resulting voltammograms obtained during the 14th cycle for the Pt/GGCo-900, $\mathrm{Pt} / \mathrm{GGCo}-1000, \mathrm{Pt} / \mathrm{GGFe}-900$ and Pt/Vulcan electrocatalysts are represented in Fig. 7b. It can be observed that during the forward scan, the current increases quickly due to the oxidation of methanol and reaches a maximum at around $0.77-0.79$ $\mathrm{V}$ for $\mathrm{Pt} / \mathrm{GCNs}$ and $0.77 \mathrm{~V}$ for Pt/Vulcan with the appearance of two overlapping oxidation peaks. In the backward scan, the re-oxidation of methanol gives rise to an anodic peak at around $0.67-0.68 \mathrm{~V}$ for all the electrocatalysts. The catalytic activity was evaluated as the current per gram of platinum at the maximum point of the anodic peak in the forward scan after subtracting the double layer contribution $\left(I_{\mathrm{f}}\right)$. These data are listed in Table 2. The values obtained for the Pt/GCNs are comparable to or even higher than the others reported in the literature for other electrocatalysts made up of Pt supported on other graphitic nanostructures (e.g. nanotubes, nanofibers, etc.). ${ }^{30}$ The high catalytic activity of the Pt/GGCo-1000 sample should be noted, as it presents an $I_{\mathrm{f}}$ current that is $\sim 50 \%$ higher than that measured for the $\mathrm{Pt} /$ Vulcan sample. The electrocatalytic activity of these catalysts was also examined by chronoamperometric experiments, which were performed in a solution of $0.1 \mathrm{M}$ of $\mathrm{CH}_{3} \mathrm{OH}$ and $0.5 \mathrm{M}$ of $\mathrm{H}_{2} \mathrm{SO}_{4}$. Fig. 7c shows the current-time curves recorded in the chronoamperometric experiment at $0.8 \mathrm{~V}$. It can be seen that the highest electrocatalytic activity is obtained with $\mathrm{Pt} / \mathrm{GCCo}-$
1000 in agreement with the voltammetric results. Fig. 7d shows the oxidation currents $\left(\mathrm{A} \mathrm{g}^{-1} \mathrm{Pt}\right)$ measured at $5 \mathrm{~s}$ for the different potential steps: $0.6 \mathrm{~V}, 0.7 \mathrm{~V}, 0.8 \mathrm{~V}$ and $0.85 \mathrm{~V}$. The highest current for all the catalysts was also obtained at $0.8 \mathrm{~V}$, which agrees with the potential of the maximum current in the cyclic voltammetry experiments (see Fig. 7b). Moreover, whereas the Pt/GGCo-900 and Pt/GGFe-900 samples have oxidation currents close to the reference material (Pt/Vulcan), the values obtained for the $\mathrm{Pt} / \mathrm{GGCo}-1000$ catalyst are considerably higher. This result is in agreement with that obtained from cyclic voltammetry and confirms the high catalytic performance of the $\mathrm{Pt} / \mathrm{GGCo}-1000$ sample.

\section{Conclusions}

In summary, graphitic carbon particles consisting of nanocapsules (diameter: $\sim 40-50 \mathrm{~nm}$, shell thickness: $\sim 10-12 \mathrm{~nm}$ ) or nanopipes (diameter: $\sim 150 \mathrm{~nm}$, wall thickness: $\sim 10-15 \mathrm{~nm}$ ) have been succesfully prepared by means of a solid-phase synthesis method that involves subjecting Fe(II) gluconate and $\mathrm{Co}$ (II) gluconate to a simple heat treatment at a moderate temperature $\left(\leq 1000{ }^{\circ} \mathrm{C}\right)$ followed by the oxidation/ removal of the metallic particles and amorphous carbon. Graphitic nanostructures prepared in this way have a high crystallinity as evidenced by TEM/SAED, HRTEM, XRD and Raman spectra. Moreover, they have relatively 
large specific surface areas in the $115-150 \mathrm{~m}^{2} \mathrm{~g}^{-1}$ range, which can be assigned to the external surface area of the graphitic nanoparticles.

The graphitic carbon nanoparticles were used as electrocatalyst supports, the Pt nanoparticles being deposited by means of a polymer-mediated polyol method. These electrocatalysts exhibited high dispersions of Pt nanoparticles, which are less than $3.2 \mathrm{~nm}$ in size and have narrow particle size distributions. What is more, the electroactive surface areas, as measured by cyclic voltammetry, are in the $65-90 \mathrm{~m}^{2} \mathrm{~g}^{-1} \mathrm{Pt}$ range. The oxidation state of the deposited platinum nanoparticles when examined by XPS is mostly one of zero oxidation $(>70 \%)$. The electrocatalytic activity of the $\mathrm{Pt} / \mathrm{GCNs}$ samples towards methanol electrooxidation was investigated by means of cyclic voltammetry and chronoamperometric experiments. We observed that these materials exhibit high electrocatalytic activities, especially the catalyst obtained from the graphitic nanoparticles resulting from the carbonization at $1000{ }^{\circ} \mathrm{C}$ of $\mathrm{Co}(\mathrm{II})$ gluconate (support: GGCo-1000). Our results show that this solid-phase synthesis offers a facile route for producing graphitic nanoparticles that may serve as excellent supports in the preparation of high-performance electrocatalysts.

\section{Acknowledgements}

The financial support for this research work provided by the Spanish MCyT (MAT2005-00262, MAT2004-01479 and FEDER) is gratefully acknowledged. M.S. acknowledges the assistance of the Spanish MCyT in awarding a FPU grant. The authors thank J. L. Baldonedo (UCM) for the TEM images of the GCNs.

\section{References}

1 T. D. Burchell, Carbon Materials for Advanced Technologies, Pergamon Press, Amsterdam, 1999.

2 (a) X. S. Zhao, F. B. Su, Q. F. Yan, W. P. Guo, X. Y. Bao, L. Lv and Z. C. Zhou, J. Mater. Chem., 2006, 16, 637; (b) H. Yang and D. Zhao, J. Mater. Chem., 2005, 15, 1217.

3 K.-Y. Chan, J. Ding, J. Ren, S. Cheng and K. Y. Tsang, J. Mater. Chem., 2004, 14, 505.

4 (a) D. S. Bethune, C. H. Kiang, M. DeVries, G. Gorman, R. Savoy, J. Vazquez and R. Beyers, Nature, 1993, 363, 605; (b) C. Journet, W. K. Maser, P. Bernier, A. Loiseau, M. L. Delachapelle, S. Lefrant, P. Deniard, R. Lee and J. E. Fischer, Nature, 1997, 388, 756; (c) M. Endo, K. Takeuchi, K. Kobori, K. Takahashi, H. W. Kroto and A. Sarkar, Carbon, 1995, 33, 873.

5 (a) A. Thess, R. Lee, P. Nikolaev, H. J. Dai, P. Petit, J. Robert, C. H. Xu, Y. H. Lee, S. G. Kim, A. G. Rinzler, D. T. Colbert, G. E. Scuseria, D. Tomanek, J. E. Fischer and R. E. Smalley, Science, 1996, 273, 483; (b) T. Guo, P. Nikolaev, A. Thess, D. T. Colbert and R. E. Smalley, Chem. Phys. Lett., 1995, 243, 49; (c) Y. Ma, Z. Hue, K. Huo, Y. Lu, Y. Hu, Y. Liu, J. Hu and Y. Chen, Carbon, $2005,43,1667$.

6 (a) J. Kong, A. M. Cassell and H. J. Dai, Chem. Phys. Lett., 1998, 292, 567; (b) A. M. Cassell, J. A. Raymakers, J. Kong and H. Dai, J. Phys. Chem. B, 1999, 103, 6484; (c) C. P. Deck and K. Vecchio, Carbon, 2005, 43, 2608; (d) C. K. Tan, K. P. Loh, J. T. L. Thong, C. H. Sow and H. Zhang, Diamond Relat. Mater., 2005, 14, 902; (e) M. Meyyappan, L. Delzeit, A. Cassell and D. Hash, Plasma Sour. Sci. Technol., 2003, 12, 205.

7 (a) F. J. Derbyshire, A. E. B. Presland and D. L. Trimm, Carbon, 1975, 13, 111; (b) H. Marsh and A. P. Warburton, Pure Appl. Chem., 1970, 20, 133; (c) A. Oya and S. Otani, Carbon, 1979, 17, 131.
8 A. Oya and H. Marsh, J. Mater. Sci., 1982, 17, 309.

9 N. I. Maksimova, O. P. Krivoruchko, G. Mestl, V. I. Zaikovskii, A. L. Chuvilin, A. N. Salanov and E. B. Burgin, J. Mol. Catal. A: Chem., 2000, 158, 301.

10 H. Marsh, D. Crawford and D. W. Taylor, Carbon, 1983, 21, 81-87.

11 (a) T. Hyeon, S. Han, Y. E. Sung, K. W. Park and Y. W. Kim, Angew. Chem., Int. Ed., 2003, 42, 4352; (b) S. Han, Y. Yun, K. W. Park, Y. E. Sung and T. Hyeon, $A d v$. Mater., 2003, 15, 1922.

12 (a) M. Sevilla and A. B. Fuertes, Carbon, 2006, 44, 468; (b) A. Oya, A. M. Yutaka and S. Otani, Fuel, 1980, 59, 595.

13 M. Sevilla, C. Sanchís, T. Valdés-Solís, E. Morallón and A. B. Fuertes, J. Phys. Chem. C, 2007, 111, 9749.

14 (a) P. I. Dosa, C. Erben, V. S. Iyer, K. P. C. Vollhardt and I. M. Wasser, J. Am. Chem. Soc., 1999, 121, 10430; (b) M. Laskoski, W. Steffen, J. G. M. Morton, M. D. Smith and U. H. F. Bunz, J. Am. Chem. Soc., 2002, 124, 13814; (c) C. N. R. Rao and A. Govindaraj, Acc. Chem. Res., 2002, 35, 998; (d) D. Jain, A. Winkel and R. Wilhelm, Small, 2006, 2, 752; (e) B. E. Hamaoui, L. Zhi, J. Wu, J. Li, N. Lucas, U. Kolb and K. Müllen, Adv. Funct. Mater., 2007, $17,1179$.

15 M. Chen and Y. Xing, Langmuir, 2005, 21, 9334.

16 R. Woods, Electroanal. Chem. Interfacial Electrochem., 1974, 49, 217-226.

17 M. Kruk, M. Jaroniec and K. P. Gadkaree, J. Colloid Interface Sci., 1997, 192, 250.

18 M. Inagaki, New carbons. Control of structure and functions, Elsevier, Amsterdam, 2000.

19 (a) F. Tuinstra and J. L. Koening, J. Chem. Phys., 1970, 53, 1126; (b) A. Sadezky, H. Muckenhuber, H. Grothe, R. Niessner and U. Pöschl, Carbon, 2005, 43, 1731.

20 P. Lespade, A. Marchand, M. Couzi and F. Cruege, Carbon, 1984, 22, 375 .

21 (a) A. Cuesta, P. Dhamelincourt, J. Laureyns, A. Martínez-Alonso and J. M. D. Tascón, J. Mater. Chem., 1998, 8, 2875; (b) D. González, M. A. Montes-Morán and A. B. García, Energy Fuels, 2003, 17, 1324; (c) Y. Zhang, G. Hu, D. O'Hare, D. Wu and Y. Sun, Carbon, 2006, 44, 1969; (d) S.-S. Tzeng, Carbon, 2006, 44, 1986.

22 N. Fujiwara, K. Yasuda, T. Ioroi and Z. Siroma, Electrochim. Acta, 2002, 47, 4079.

23 (a) S. D. Knights, K. M. Colbow, J. St-Pierre and D. P. Wilkinson, J. Power Sources, 2004, 127, 127; (b) D. A. Stevens and J. R. Dahn, Carbon, 2005, 43, 179.

24 (a) X. Zhang and K.-Y. Chan, Chem. Mater., 2003, 15, 451; (b) T. Onoe, S. Iwamoto and M. Inoue, Catal. Commun., 2007, 8, 701; (c) J. Prabhuram, T. S. Zhao, Z. X. Liang and L. R. Chen, Electrochim. Acta, 2007, 52, 2649.

25 P.-L. Kuo, W.-F. Chen, H.-Y. Huang, I.-C. Chang and S. A. Dai, J. Phys. Chem. B, 2006, 110, 3071.

26 K. Yamamoto, D. M. Kolb, R. Kötz and G. Lehmpfuhl, $J$. Electroanal. Chem., 1979, 96, 233.

27 (a) G. A. Attard, J. E. Gillies, C. A. Harris, D. J. Jenkins, P. Johnston, M. A. Price, D. J. Watson and P. B. Wells, Appl. Catal. A, 2001, 222, 393; (b) R. Gómez and J. Clavilier, J. Electroanal. Chem., 1993, 354, 189.

28 (a) J. Fournier, G. Faubert, J. Y. Tilquin, R. Côté, D. Guay and J. P. Dodelet, J. Electrochem. Soc., 1997, 144, 145-154; (b) J. Perez, E. R. Gonzalez and E. A. Ticianelli, Electrochim. Acta, 1998, 44, 1329-1339; (c) Y. C. Liu, X. P. Qiu, Y. Q. Huang and W. T. Zhu, Carbon, 2002, 40, 2375-80; (d) J. Marie, S. Berthon-Fabry, P. Achard, M. Chatenet, A. Pradourat and E. Chainet, J. Non-Cryst. Solids, 2004, 350, 88-96; (e) S. H. Joo, C. Pak, D. J. You, S.-A. Lee, H. I. Lee, J. M. Kim, H. Chang and D. Seung, Electrochim. Acta, 2006, 52, 1618-1626; $(f)$ B. Xu, X. Yang, X. Wang, J. Guo and X. Liu, J. Power Sources, 2006, 162, 160-164; ( $g$ ) Y. Tang, Z. Lingling, Y. Wang, Y. Zhou, Y. Gao, C. Liu, W. Xing and T. Lu, J. Power Sources, 2006, 162, 124-31.

29 F. Zaragoza-Martín, D. Sopeña-Escario, E. Morallón, and C. Salinas-Martínez de Lecea,J. Power Sources, 2007, DOI: 10.1016/j.jpowsour.2007.06.078.

30 (a) Z. Liu, X. Y. Ling, X. Su and J. Y. Lee, J. Phys. Chem. B, 2004, 108, 8234-8240; (b) H. Tang, J. Chen, L. Nie, D. Liu, W. Deng, Y. Kuang and S. Yao, J. Colloid Interface Sci., 2004, 269, 26-31; 
(c) Y. Mu, H. Liang, J. Hu, L. Jiang and L. Wan, J. Phys. Chem. B, 2005, 109, 22212-22216; (d) Y.-T. Kim and T. Mitani, J. Catal.,
2006, 238, 394-40; (e) F. Sen and G. Gökagaç, J. Phys. Chem. C, 2007, 111, 1467-1473.

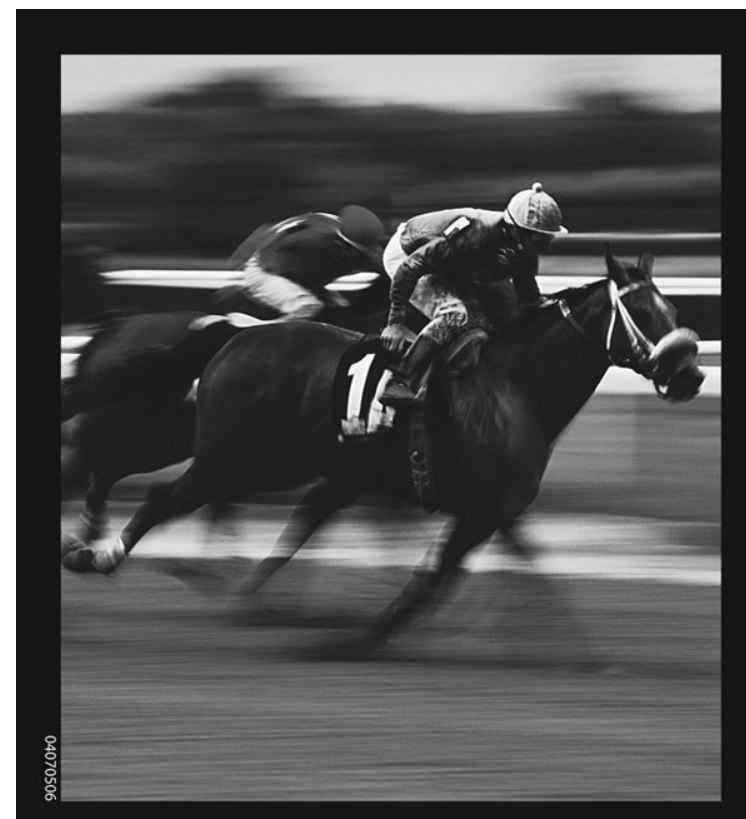

RSCPublishing

\section{Fast Publishing? Ahead of the field}

To find out more about RSC Journals, visit www.rsc.org/journals 